Article

\title{
Hydrodynamics of Pulsed Fluidized Bed of Ultrafine Powder: Fully Collapsing Fluidized Bed
}

\author{
Mohammad Asif *(D), Ebrahim H. Al-Ghurabi, Abdelhamid Ajbar and Nadavala Siva Kumar(i) \\ Department of Chemical Engineering, King Saud University, P.O. Box 800, Riyadh 11421, Saudi Arabia; \\ ealghurabi@ksu.edu.sa (E.H.A.-G.); aajbar@ksu.edu.sa (A.A.); snadavala@ksu.edu.sa (N.S.K.) \\ * Correspondence: masif@ksu.edu.sa; Tel.: +966-56-981-7045
}

Received: 8 June 2020; Accepted: 7 July 2020; Published: 9 July 2020

\begin{abstract}
The processing of fine and ultrafine particles using a fluidized bed is challenging in view of their unpredictable hydrodynamic behavior due to interparticle forces. The use of assisted fluidization techniques in such cases can be effective in improving the bed hydrodynamics. This work investigates the dynamics of pulsed fluidized bed of ultrafine nanosilica subjected to square-wave flow pulsations. The pulse duration used in this study is sufficient to allow the complete collapse of the pulsed fluidized bed between two consecutive flow pulsations. The proposed pulsation strategy is carefully implemented using electronic mass flow controllers with the help of analog output signals from data acquisition system. Given that the different regions of the fluidized bed exhibit varying dynamics, which together contribute to overall bed dynamics, the bed transients in the upper, central, and lower regions of the fluidized bed are monitored using several sensitive pressure transducers located along the height of the bed. The effect of the flow pulsation on the hydrodynamics of the fluidized bed is rigorously characterized. A significant reduction in the minimum fluidization velocity was obtained and an increase in the bed homogeneity was observed due to flow pulsations. The frequency domain analysis of the signals clearly delineated the frequency of the various events occurring during the fluidization.
\end{abstract}

Keywords: pulsed fluidized bed; ultrafine powder; bed dynamics; flow pulsation; nanoagglomerates

\section{Introduction}

Fluidized beds are widely used in particle processing operations owing to intimate contact between phases and efficient mixing that lead to high rates of heat and mass transfer. Moreover, unlike the inverse square dependence of the pressure drop on the particle size for fixed beds at low velocities, the fluidized bed mode of operation limits the pressure drop to the effective weight of the bed. This feature of the of fluidized bed allows the use of small particles with high effectiveness factor as catalytic support, thereby ensuring improved catalyst utilization that ultimately results in enhanced process efficiency.

Fine and ultra-fine particles possess extremely high specific surface areas that can tremendously enhance the surface-based rate processes. However, the extremely small particle sizes lead to strong interparticle forces. Therefore, such particles often exhibit unpredictable hydrodynamics when processed using fluidized beds. The interrelation of particle sizes with their fluidization hydrodynamics has been pointed out by Geldart [1], who classified fine particles with a diameter less than $30 \mu \mathrm{m}$ as group $C$ because of their cohesive behavior. Such particles' fluidization behavior is generally characterized by agglomeration, channeling and gas by-passing, resulting in poor interphase mixing and other non-homogeneities, which if not properly addressed can compromise their effective utilization $[2,3]$. 
The common strategy used to improve the fluidization hydrodynamics is the augmentation of extra energy to the bed of particles to overcome interparticle forces, thereby promoting de-agglomeration and eliminating bed non-homogeneities. Common assisted fluidization techniques are based on the use of acoustics [4-8], particle-mixing [9-15], flow pulsations [16-26], and mechanical vibrations [27-33]. The combination of two of assisted fluidization techniques has also been suggested in some cases [15,34-36].

The successful scale up of any assisted fluidization technique will ultimately depend upon its cost-effectiveness. Flow pulsation, unlike other assisted fluidization strategies, is an especially promising technique given that no additional energy input is required in its implementation. The bed is subjected to intense mixing due to periodic changes in the velocity of the fluidizing medium, which invariably results in a significant improvement in the fluidization hydrodynamic. For example, pulsating flow was used to improve the bed homogeneity and significantly reduce the drying time of pharmaceutical granules [19]. Significant reduction in the minimum fluidization velocity $\left(U_{m f}\right)$ and improvement in the bed homogeneity have been observed in a bed of hydrophilic nanopowder subjected to flow pulsations [20]. Another study has reported improved fluidization behavior and approximately $72 \%$ reduction in the $\mathrm{U}_{\mathrm{mf}}$ with pulsed gas flow [21]. The collapse data of a pulsed fluidized bed have also suggested a significant decrease in the size of nanoagglomerates [22]. However, the mean agglomerate diameter evaluated from the bed collapse data was not affected by the pulsation frequency [23]. The flow pulsation has helped to decrease the $U_{\mathrm{mf}}$ and enhance the fluidization hydrodynamics of cohesive powder of micron-sized particles [24]. Even low frequency pulsations have proved to significantly improve the hydrodynamics of ultrafine hydrophilic nanopowder with strong agglomeration tendencies [26].

A close look on the experimental setup used for assisted fluidization technique of flow pulsation reveals that most studies have relied on the solenoid valve to introduce the square-wave flow pulsations $[20,24,35]$. However, this configuration leads to pressure buildup in the inlet line when the flow is stopped during the "off" position of the solenoid valve. Consequently, when the flow starts again after the interruption, the inlet line pressure buildup causes a flow impulse in the bed leading to a pressure-drop spike. This phenomenon is more prominent for low velocity and low frequency pulsations [23]. Recently, Zhu et al. [37] suggested using a special purpose solenoid valve that vents the fluidizing gas to the atmosphere during the "off" position. However interesting, its usefulness is limited only to cases where the fluidizing gas is the ambient air. Therefore, instead of using solenoid valve, electronic mass flow controllers are used in this study for a precise control of the gas flow to the fluidized bed. The flow and its duration are accurately controlled using analog output from an 18-bit data acquisition system. Another aspect of the fluidized bed hydrodynamics that has recently attracted attention is the non-uniformity along the height of the fluidized bed. Agglomerates present in the lower region of a mechanically vibrated fluidized bed of nanopowders were reported to be approximately 10 times larger than the ones in the upper region of the bed. Stirring using an impeller in the bottom of the bed somehow helped to mitigate this axial agglomerate size non-uniformity. However, the combination of assisted-fluidization techniques of vibration and stirring failed to completely eliminate the size segregation of agglomerates [36]. Therefore, the pulsed bed dynamics is carefully monitored in the upper, central, and lower regions of the fluidized bed using several sensitive pressure transducers located along the height of the fluidized bed to delineate the local fluidization behavior. Since the pulsation frequency has been reported to affect the behavior of pulsed beds [24,35], the pulse duration in this study is fixed to ensure complete collapse of the bed between two consecutive pulsations. Besides analyzing the frequency response of bed transients, the experimental data are processed to evaluate the effect of pulsation on the mean pressure drop characteristics of different regions of the fluidized bed and the minimum fluidization velocity. 


\section{Experimental}

The schematic of the experimental setup is shown in Figure 1. The test-section was a 1.5-m long transparent cylindrical Plexiglas column of $70 \mathrm{~mm}$ internal diameter. A $0.5-\mathrm{m}$ long calming section before the test-section was used to eliminate the entry effects of the inlet fluidizing air. Located between the test and calming sections, a $9 \mathrm{~mm}$ thick perforated plate with $2 \mathrm{~mm}$ holes arranged on a square pitch and $4 \%$ fractional open area was used as distributor to ensure uniform air distribution across the cross-section of the test-section. Such a design of the distributor was used to ensure sufficient pressure drop across the distributor and eliminate the dead-zones in the distributor region [38]. A fine nylon mesh was used to cover the distributor to prevent the clogging of its perforations with the fine solid particles present in the bed. Another $0.5-\mathrm{m}$ long disengagement section of $140 \mathrm{~mm}$ internal diameter was placed above the test-section for the suppression of the carryover loss of the solid particles present in the bed. Pressurized air from the central compressed air supply available at $3 \mathrm{~atm}$. gauge pressure was used for the experiments.

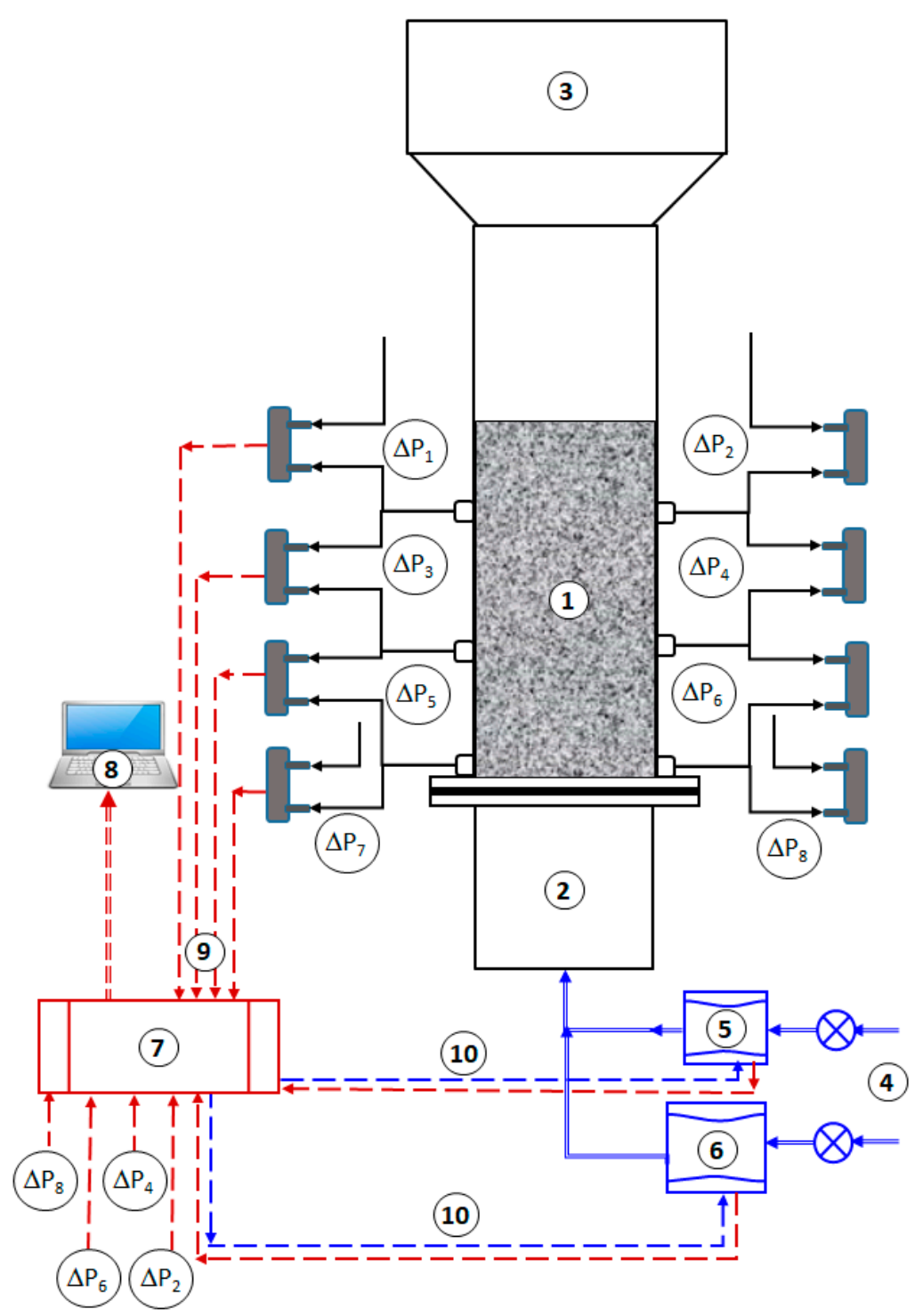

Figure 1. Experimental setup. (1) Fluidized bed test section; (2) Calming section; (3) Disengagement section; (4) Compressed air supply; (5) Low range mass flow controller; (6) High range mass flow controller; (7) Data acquisition system; (8) Computer with LabVIEW software; (9) Analog input signals (red broken lines); (10) Analog output signals (blue broken lines). 
Hydrophilic fumed nanosilica (AEROSIL 200) with a reported surface area of $200 \mathrm{~m}^{2} / \mathrm{g}$ was used in our experiments. The sample was sieved to remove the large agglomerates. The particle size analysis results of dry nanosilica sample obtained from using Mastersizer 2000 (Malvern Panalytical Ltd, Malvern, UK) are shown in Figure 2. Although the reported primary size the nanoparticles was $12 \mathrm{~nm}$, the average size was found to be $12.5 \mu \mathrm{m}$ due to their agglomeration. The scanning electron microscope (SEM) image of sieved sample is shown in Figure 3. While a few agglomerates were as large as $50 \mu \mathrm{m}$, most agglomerates size appears to be approximately $10 \mu \mathrm{m}$. Thus, wide size distribution obtained in the particle size analysis was confirmed from the SEM imaging.

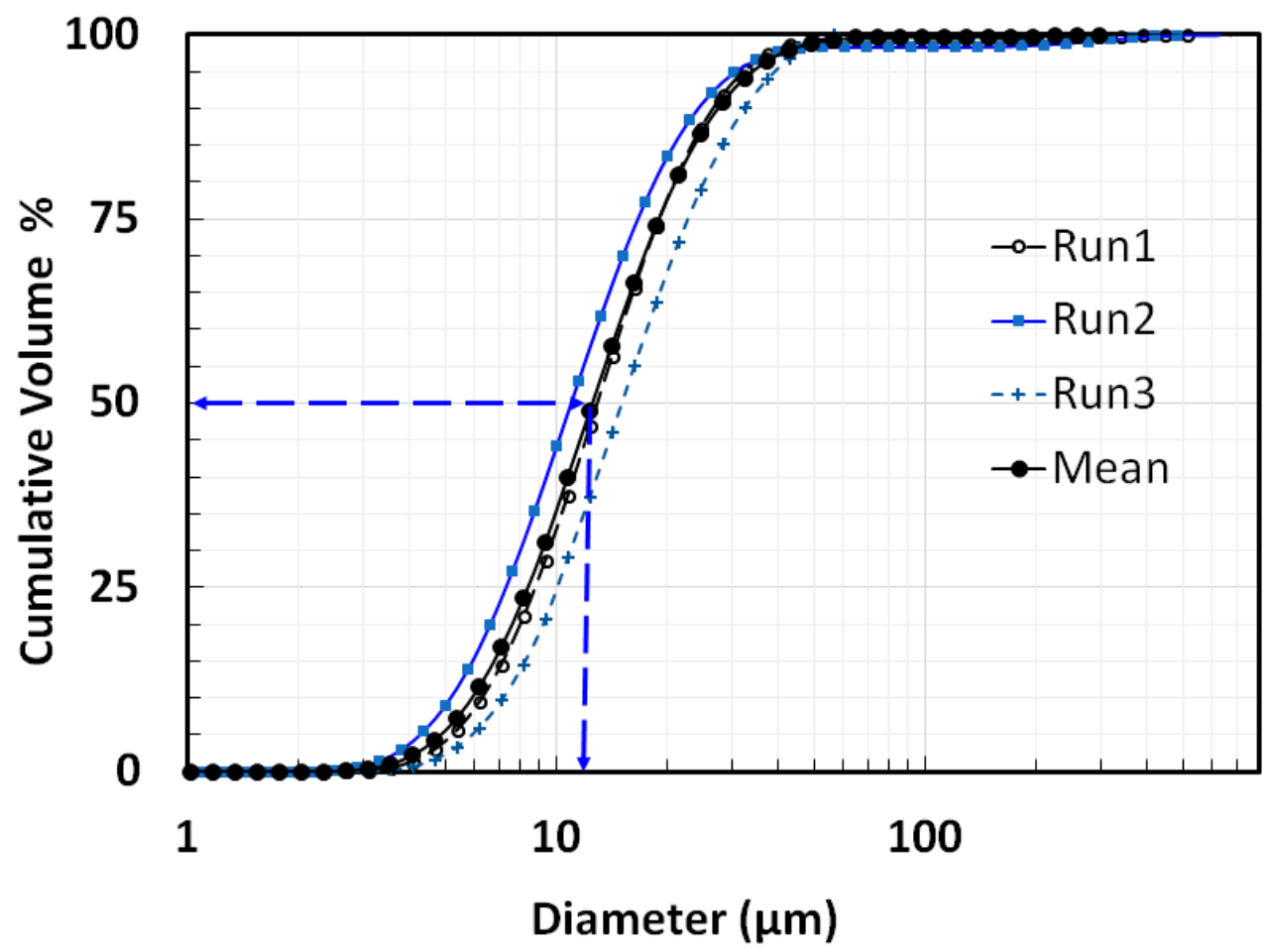

Figure 2. Cumulative particle size distribution of dry sample of sieved nanosilica.

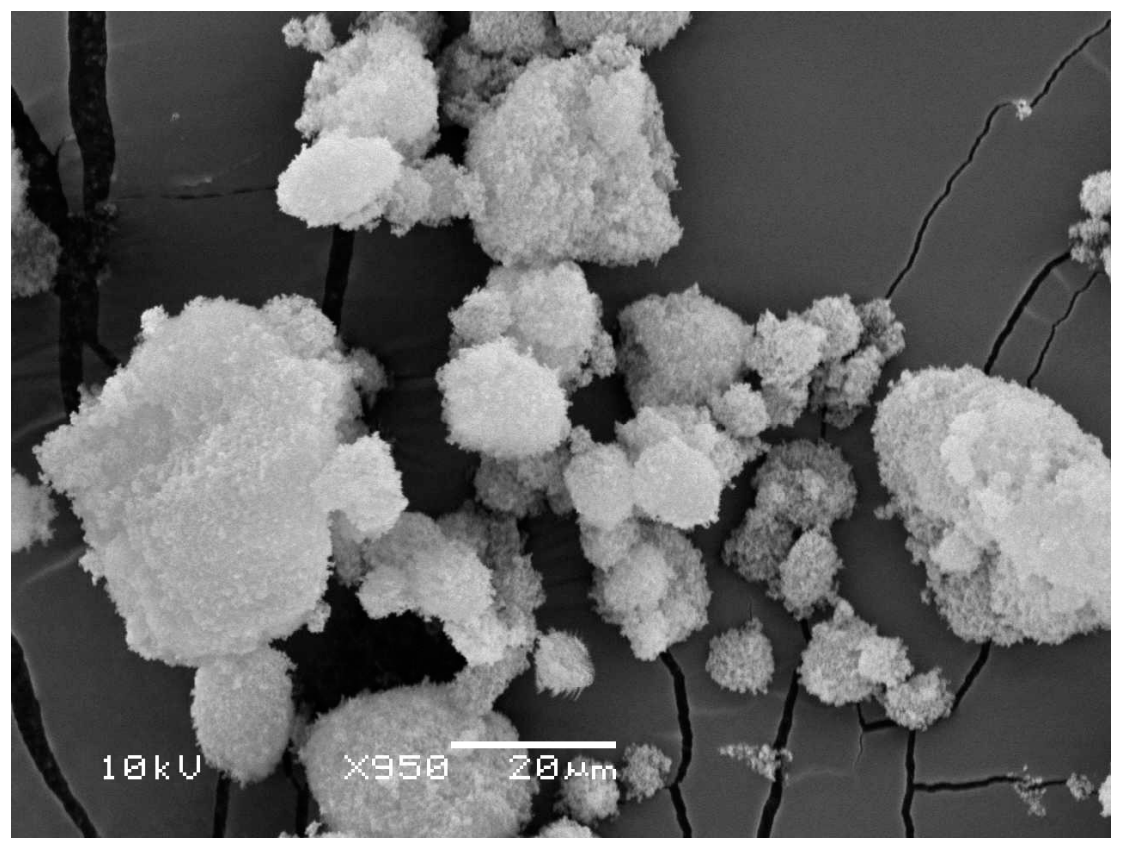

Figure 3. SEM image showing size distribution of nanoagglomerates of sieved sample. 
Pressure transients in the different regions of the bed were carefully monitored using several sensitive pressure transducers with a response time of $1 \mathrm{~ms}$. The lowest pressure tap was $11 \mathrm{~mm}$ above the distributor plate, whereas the two other taps were located at a distance of $110 \mathrm{~mm}$ and $230 \mathrm{~mm}$ from the distributor. As shown in Figure 1, two pressure taps were located at diametrically opposite sides of the test-section to monitor the occurrence of radial non-uniformities. Thus, $\Delta \mathrm{P}_{1}$ (i.e., left side) and $\Delta \mathrm{P}_{2}$ (i.e., right side) monitored the transients in the upper region of the test-section. The upper port of $\Delta \mathrm{P}_{1}$ and $\Delta \mathrm{P}_{2}$ was open to the atmosphere, whereas the lower port was connected to the pressure tap located $230 \mathrm{~mm}$ above the distributor. Similarly, $\Delta \mathrm{P}_{3}$ (i.e., left side) and $\Delta \mathrm{P}_{4}$ (i.e., right side) recorded the bed transients in the middle region of the fluidized bed. These pressure transducers were connected to pressure taps located $110 \mathrm{~mm}$ and $230 \mathrm{~mm}$ above the distributor. The bed dynamics in the lower region was monitored using pressure transducers $\Delta \mathrm{P}_{5}$ (i.e., left side) and $\Delta \mathrm{P}_{6}$ (i.e., right side) with their upper and lower ports connected, respectively, with taps located $110 \mathrm{~mm}$ and $11 \mathrm{~mm}$ above the distributor (Figure 1). Moreover, two pressure transducers $\Delta \mathrm{P}_{7}$ and $\mathrm{P}_{8}$ were used for monitoring global pressure transients. In this case, the lower port was connected with lower pressure tap, whereas the upper port was open to the atmosphere. Thus, the sum of local pressure drops would ideally yield the global pressure drop as follows:

$$
\begin{aligned}
& \Delta P_{1}+\Delta P_{3}+\Delta P_{5}=\Delta P_{7} \\
& \Delta P_{2}+\Delta P_{4}+\Delta P_{6}=\Delta P_{8}
\end{aligned}
$$

A fine nylon mesh screen was used to cover the openings of the pressure taps to prevent the clogging of the pressure tap lines due to the entrainment of the solid particles present in the bed. To ensure the accuracy of measurements, Fluke 718 Pressure Calibrator (Everett, WA, USA) were used for the calibration of the pressure transducers.

The pressure transducers were connected to a USB-6289 data acquisition system (DAQ), which is a $32 \mathrm{AI}(18-\mathrm{Bit}, 625 \mathrm{kS} / \mathrm{s}), 4 \mathrm{AO}(2.86 \mathrm{MS} / \mathrm{s})$ system obtained from National Instruments, located in Texas, US. The sampling frequency of the pressure transients was kept at $100 \mathrm{~Hz}$ to record 100 samples in one second. This sampling rate was sufficient to delineate the bed dynamics.

Inlet flow of the fluidizing air to the test-section was carefully monitored using two electronic mass controllers of different ranges, which were connected to separate stable supplies of compressed air. Both mass flow controllers were connected to DAQ, which controlled flow rates of the input air. Two DAQ analog outputs were used (i.e., one for each mass flow controller) to generate the flow pulsation of required frequency. National Instruments LabVIEW software was used to generate pulsation signals. Such signals were transmitted to DAQ, and subsequently to the mass flow controllers as an analog output in volts corresponding to the required flowrate in liters per minute (LPM).

The fumed nanosilica sample was first carefully sieved to remove large agglomerates, which often formed due to storage over time. A total of $62 \mathrm{~g}$ of the sieved nanosilica was then loaded into the test-section with frequent tapping. The bed material was left overnight to allow its settling. These steps were taken to ensure bed homogeneity before conducting the experiments. The static bed height was $370 \mathrm{~mm}$.

The experimental strategy was a two-step procedure. In the first step, the hydrodynamics of the conventional unassisted fluidization was studied for a wide range of velocities. A total of 18 different velocity steps were considered by increasing and then decreasing the flow rate of the fluidizing gas. Each velocity step lasted for $80 \mathrm{~s}$. Hydrodynamics of the fluidized bed subjected to flow pulsations was rigorously investigated in the second stage of this work. Similar to unassisted fluidization, 18 velocity step changes were introduced by progressively increasing the velocity during the fluidization cycle followed by a similar step-wise decrease during the defluidization cycle. Each velocity step in the experiment lasted for $50 \mathrm{~s}$. The inlet flow was regularly pulsed with the help of DAQ-controlled mass flow controllers at a frequency of $0.1 \mathrm{~Hz}$. This process composed of $5 \mathrm{~s}$ of uninterrupted inlet air flow to the bed followed by $5 \mathrm{~s}$ of complete flow interruption (i.e., zero flow). 
To ensure the reproducibility of the experimental data, two experimental runs were conducted for the same set of experimental conditions. An excellent agreement was mostly observed between the two runs. To verify the reliability of pressure drop measurements of different pressure transducers, the local pressure drops of all the three regions, namely lower, middle, and upper regions, were summed using Equation (3) as follows,

$$
\frac{\left(\Delta P_{1}+\Delta P_{2}\right)}{2}+\frac{\left(\Delta P_{3}+\Delta P_{4}\right)}{2}+\frac{\left(\Delta P_{5}+\Delta P_{6}\right)}{2}=\sum \Delta P
$$

and compared with the global pressure drop across the bed, which was evaluated as follows,

$$
\frac{\left(\Delta P_{7}+\Delta P_{8}\right)}{2}=\sum \Delta P
$$

The results of the comparison for fluidization and defluidization are shown in Figure 4 . The observed excellent agreement confirmed the reliability of the pressure drop measurements in the experiments.

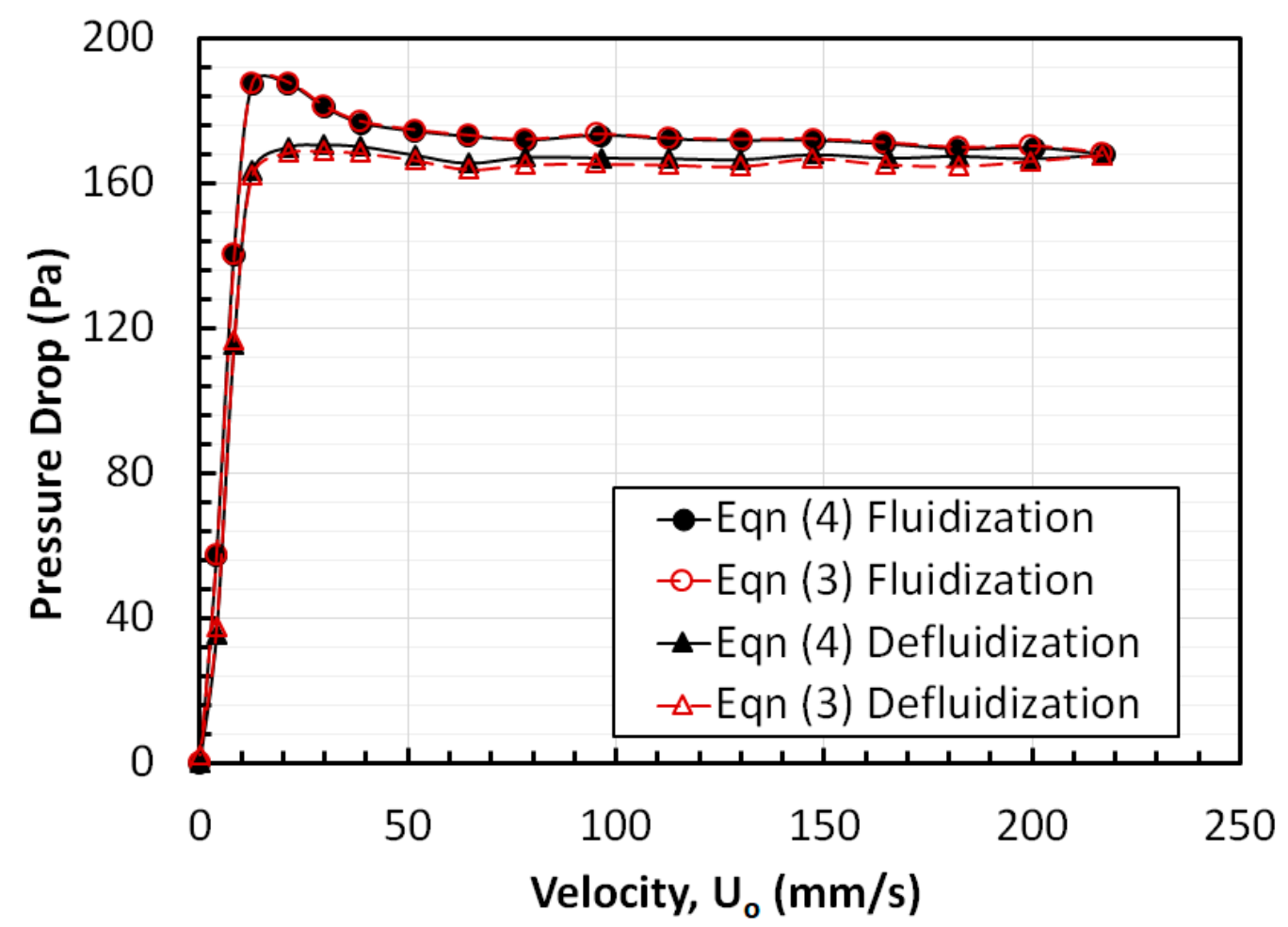

Figure 4. Comparison of pressure drops measurement using local and global pressure drops.

\section{Results and Discussion}

The velocity and the overall pressure drop data of a single complete unassisted fluidization experimental run is presented in Figure $5 \mathrm{a}$. There are 18 velocity steps of $80 \mathrm{~s}$ duration in the fluidization cycle of the experiment followed by an equal number of velocity steps during the defluidization cycle. Even a small change in the velocity at small flows causes a big change in the pressure drop due to the fixed bed mode of fluid-solid contact. When the bed is fluidized, the change in the velocity hardly affects the magnitude of the pressure drop. However, the bed dynamics showed substantial fluctuations. During the defluidization cycle of the experiment, the pressure drop fluctuations show significant attenuation due to greater bed homogeneity, which was also reflected by a relatively low pressure drop when the bed settles at low velocities. 


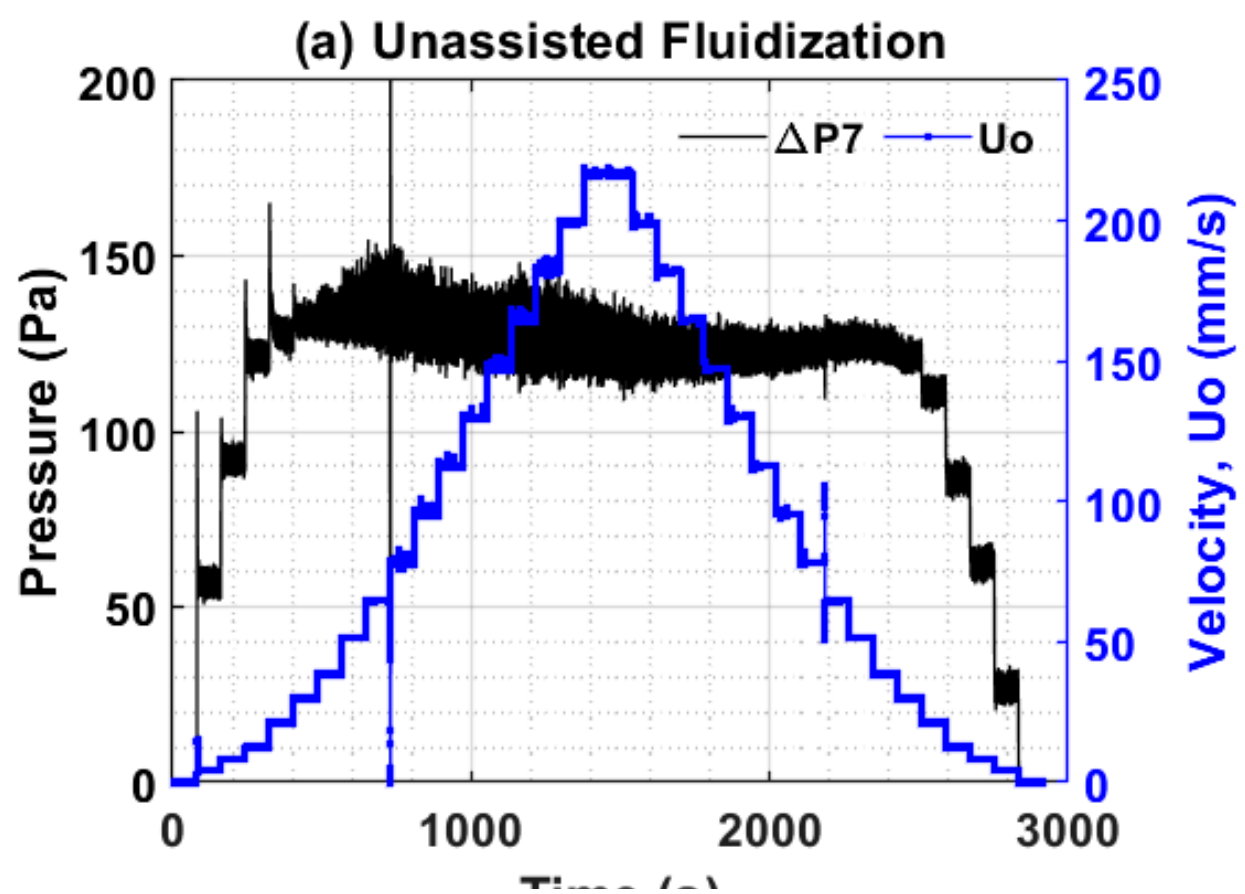

(b) Pulsed Fluidization

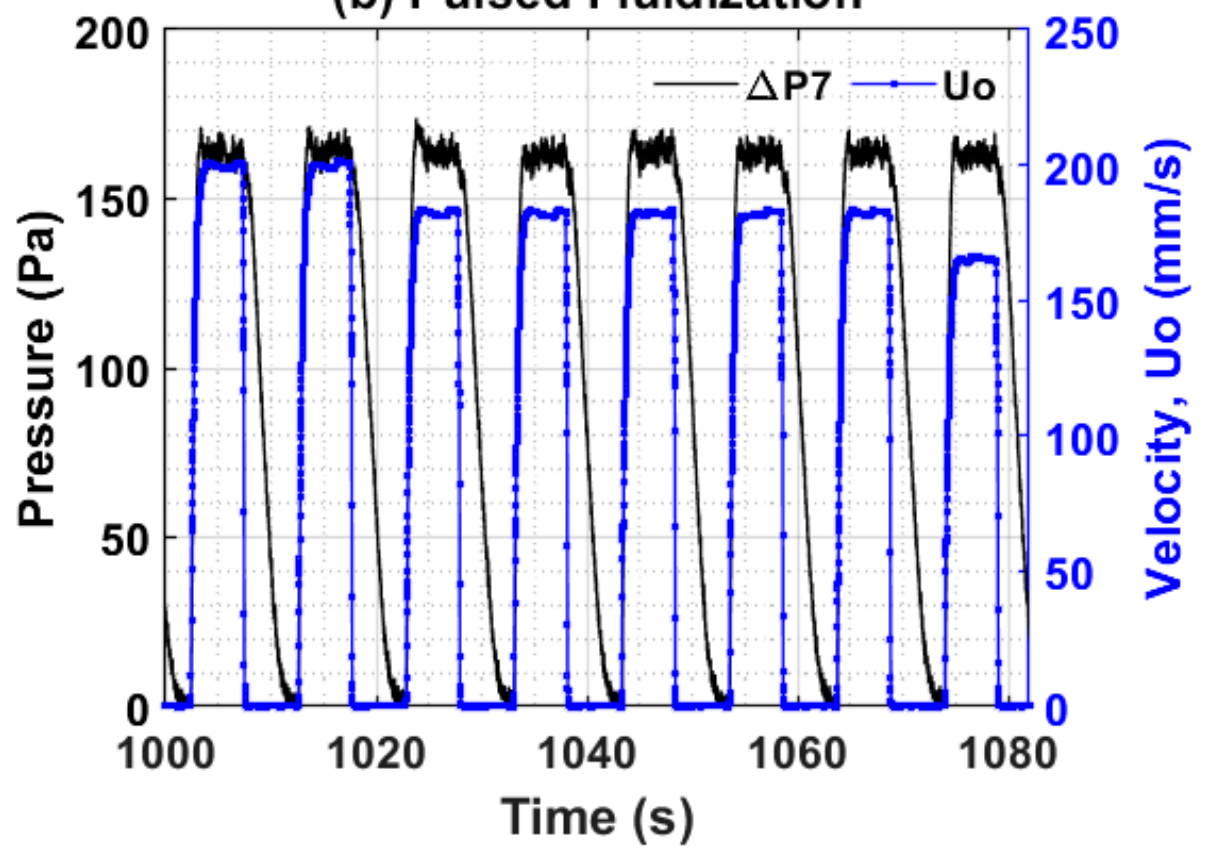

Figure 5. Velocity $\left(\mathrm{U}_{\mathrm{o}}\right)$ and overall pressure drop transients $\left(\Delta P_{7}\right)$ for $(\mathbf{a})$ unassisted fluidization and (b) pulsed fluidization.

Figure $5 \mathrm{~b}$ presents the case of pulsed fluidized bed for the duration of $80 \mathrm{~s}$ lasting from 1000s to 1080s. There are two pulses of $200 \mathrm{~mm} / \mathrm{s}$, five pulses of $182 \mathrm{~mm} / \mathrm{s}$, and one pulse of $165 \mathrm{~mm} / \mathrm{s}$. Each $50 \mathrm{~s}$ velocity step was in fact composed of five identical square pulses as observed for the case of $182 \mathrm{~mm} / \mathrm{s}$ in the figure. The global pressure drop transients are also shown in the figure. Evidently, when the flow pulse begins, the bed shows a simultaneous rapid increase in the pressure drop along with the velocity. Although the velocity shows an instantaneous response to the end of the flow pulse, there was nevertheless a delay of approximately 5 seconds in the completion of the bed collapse process. The end of the collapse process was indicated by the zero pressure drop across the fluidized bed. Therefore, 
we choose $0.1 \mathrm{~Hz}$ flow pulsation in this study to ensure the complete collapse of the fluidized bed between two consecutive pulses.

The frequency spectra for both cases are shown in Figure 6. A peak at $0.01265 \mathrm{~Hz}$ for the unassisted fluidization corresponds to an event with a time interval of $80 \mathrm{~s}$, which in the present study are velocity steps of $80 \mathrm{~s}$ duration. A prominent peak at approximately $0.1 \mathrm{~Hz}$ in Figure $6 \mathrm{~b}$ corresponds to flow pulsations of $10 \mathrm{~s}$ duration. Another smaller peak at $0.02 \mathrm{~Hz}$ for the pulsed fluidization correspond to velocity steps of 50 seconds.
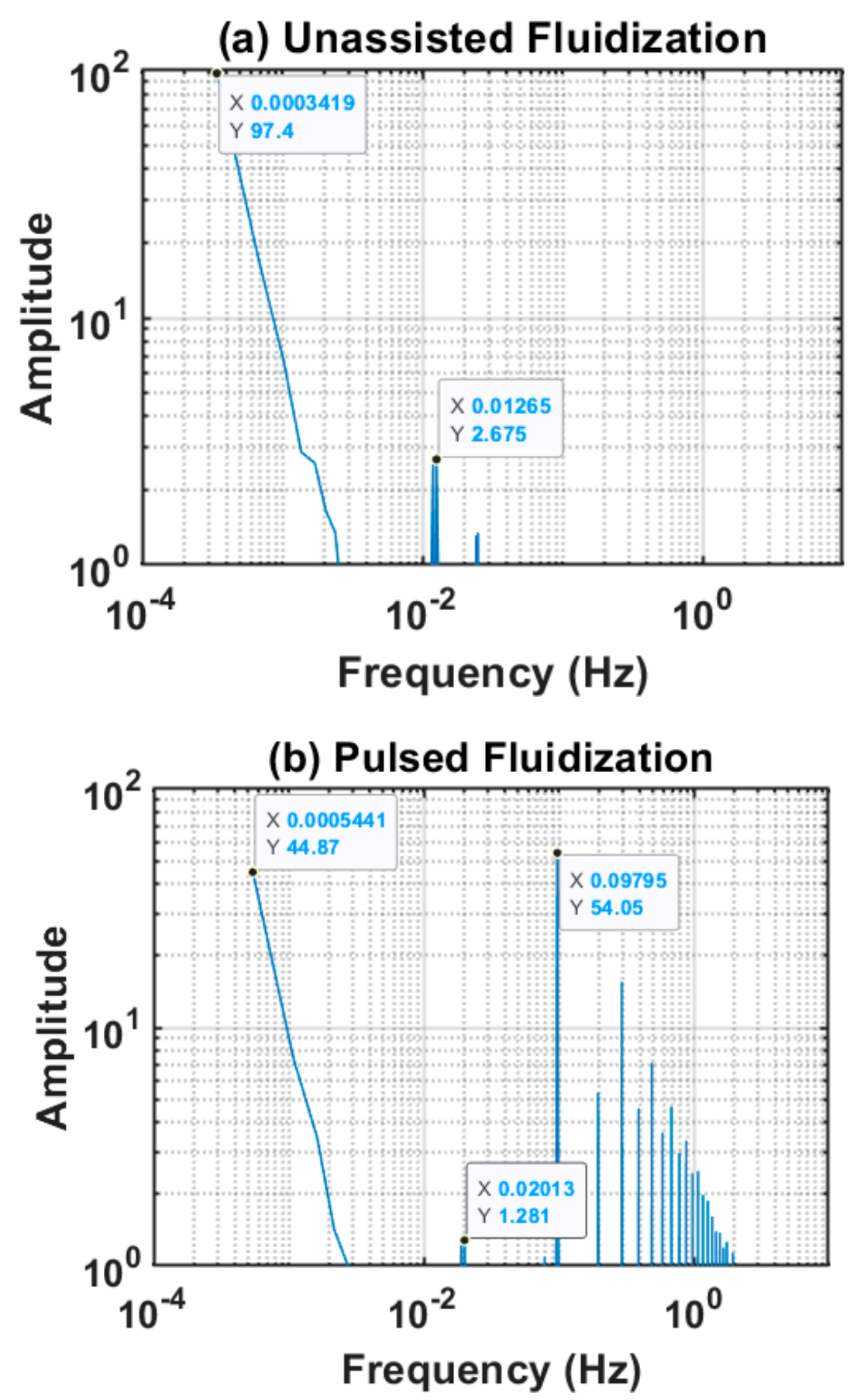

Figure 6. Frequency spectra of velocity. (a) unassisted fluidization; (b) pulsed fluidization.

Figure 7 shows pulsed bed dynamics considering two identical pulses at four different velocities. The velocity is depicted on the right-hand side, whereas the overall bed and lower region dynamics are 
represented on the left-hand side of the figure. The pressure drop is low at low velocities (i.e., $4 \mathrm{~mm} / \mathrm{s}$ ). A threefold increase in the velocity to $12 \mathrm{~mm} / \mathrm{s}$ leads to a several fold increase in the pressure drop due to the fixed bed mode of gas-solid contact prevailing at this velocity. However, another fivefold increase (i.e., $65 \mathrm{~mm} / \mathrm{s}$ ) in the velocity fails to cause any increase in the pressure drop. Instead, a small decrease in the pressure drop is observed owing to the fluidization of the bed material. Further increase in the velocity to $165 \mathrm{~mm} / \mathrm{s}$ does not affect the overall pressure drop (i.e., $\Delta P_{7}$ ), which is usually equal to the effective weight of the fluidized bed.

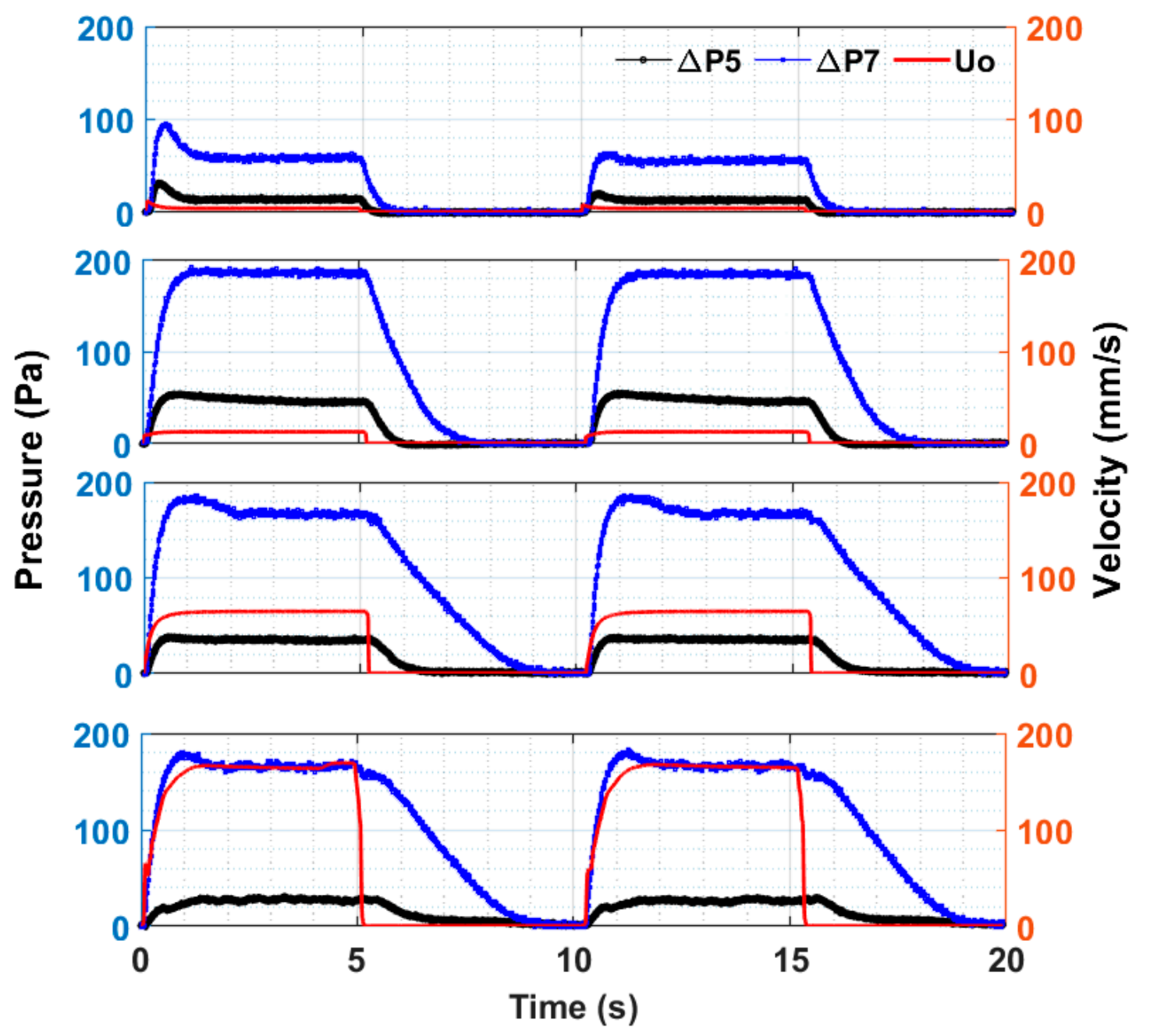

Figure 7. Overall $\left(\Delta P_{7}\right)$ and lower region $\left(\Delta P_{5}\right)$ pressure transients for $U_{o}=4 \mathrm{~mm} / \mathrm{s}, 12 \mathrm{~mm} / \mathrm{s}, 65 \mathrm{~mm} / \mathrm{s}$, and $165 \mathrm{~mm} / \mathrm{s}$ in pulsed fluidized beds.

The pulsed bed expansion shows rather instantaneous response to the step change in the fluidization velocity. Similarly, the bed collapse starts as soon as the flow to the bed is discontinued. However, the collapse process shows a slower response. Interestingly, the total time of the collapse remains relatively unaffected even when the collapse of a fully fluidized bed is initiated at two widely different velocities. For example, the collapse time is approximately same for $65 \mathrm{~mm} / \mathrm{s}$ and $165 \mathrm{~mm} / \mathrm{s}$ despite a threefold difference in the two velocities. Moreover, the collapse time is significantly different for different regions of the fluidized bed. The lower part of the pulsed fluidized bed shows a much shorter settling time than the rest of the bed since $\Delta P_{5}$ attains zero value significantly before $\Delta P_{7}$.

The bed dynamics of the upper region of the pulsed bed is shown in Figure 8 along with the global dynamics. In spite of obvious similarities with Figure 7, there is however an important difference. Specifically, the upper region shows slower response than the lower region of the bed. The pressure 
drop profile of the upper region merges with its global counterpart after approximately $3 \mathrm{~s}$ since the beginning of the collapse process. Thus, the slower dynamics of the upper region controls the overall bed collapse process.

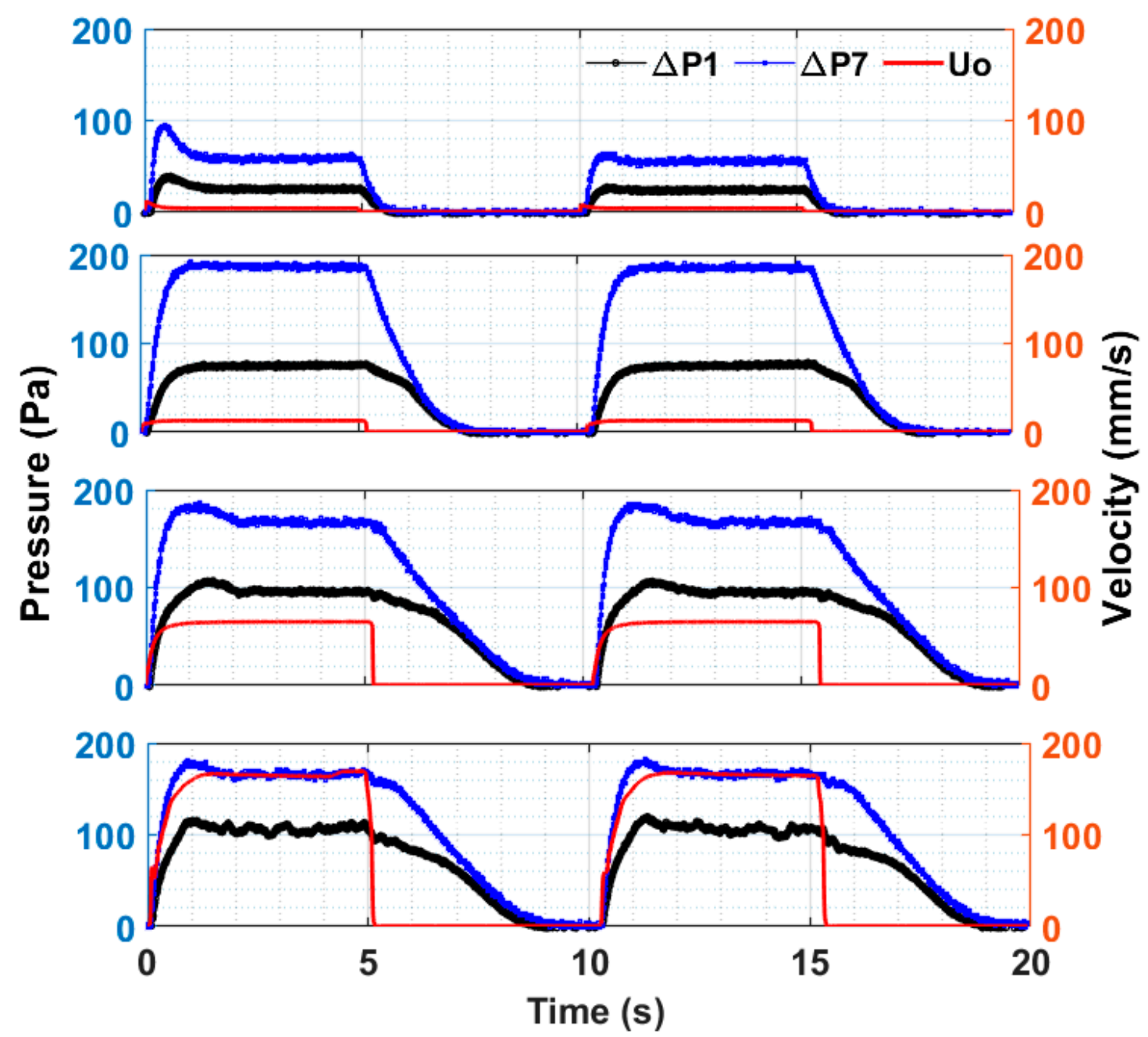

Figure 8. Overall $\left(\Delta P_{7}\right)$ and upper region $\left(\Delta P_{1}\right)$ pressure transients for $U_{\mathrm{o}}=4 \mathrm{~mm} / \mathrm{s}, 12 \mathrm{~mm} / \mathrm{s}, 65 \mathrm{~mm} / \mathrm{s}$, and $165 \mathrm{~mm} / \mathrm{s}$ in pulsed fluidized beds.

Figure 9 shows the frequency responses of unassisted and pulsed fluidized beds. As the representative of the overall bed dynamics, the global pressure drop transients of the fluidization are considered in the figure. The data are first detrended by ensuring zero value of the mean pressure drop before analyzing the frequency response of the signal. When the velocity is very low (e.g., $4 \mathrm{~mm} / \mathrm{s}$ ), fluctuations are hardly observed in the unassisted fluidized bed because of the fixed-bed mode of the gas-solid contact. However, when the velocity is increased to $12 \mathrm{~mm} / \mathrm{s}$, a relatively prominent peak is observed at an extremely low frequency even though the bed is not fluidized. Thus, the occurrence of an event is indicated, most probably by the movement of a stray air bubble rising through the bed. As the velocity is increased further to $65 \mathrm{~mm} / \mathrm{s}$, small amplitude events are observed to occur in the frequency range of 1-20 Hz due to the formation of bubbles and the movement of agglomerates owing to the passage of air through the bed of the nanosilica. Increasing the velocity further to $165 \mathrm{~mm} / \mathrm{s}$ has enhanced the magnitude of fluctuations given the rather vigorous motion introduced in the solid particles due to higher velocity of the fluidizing air. 

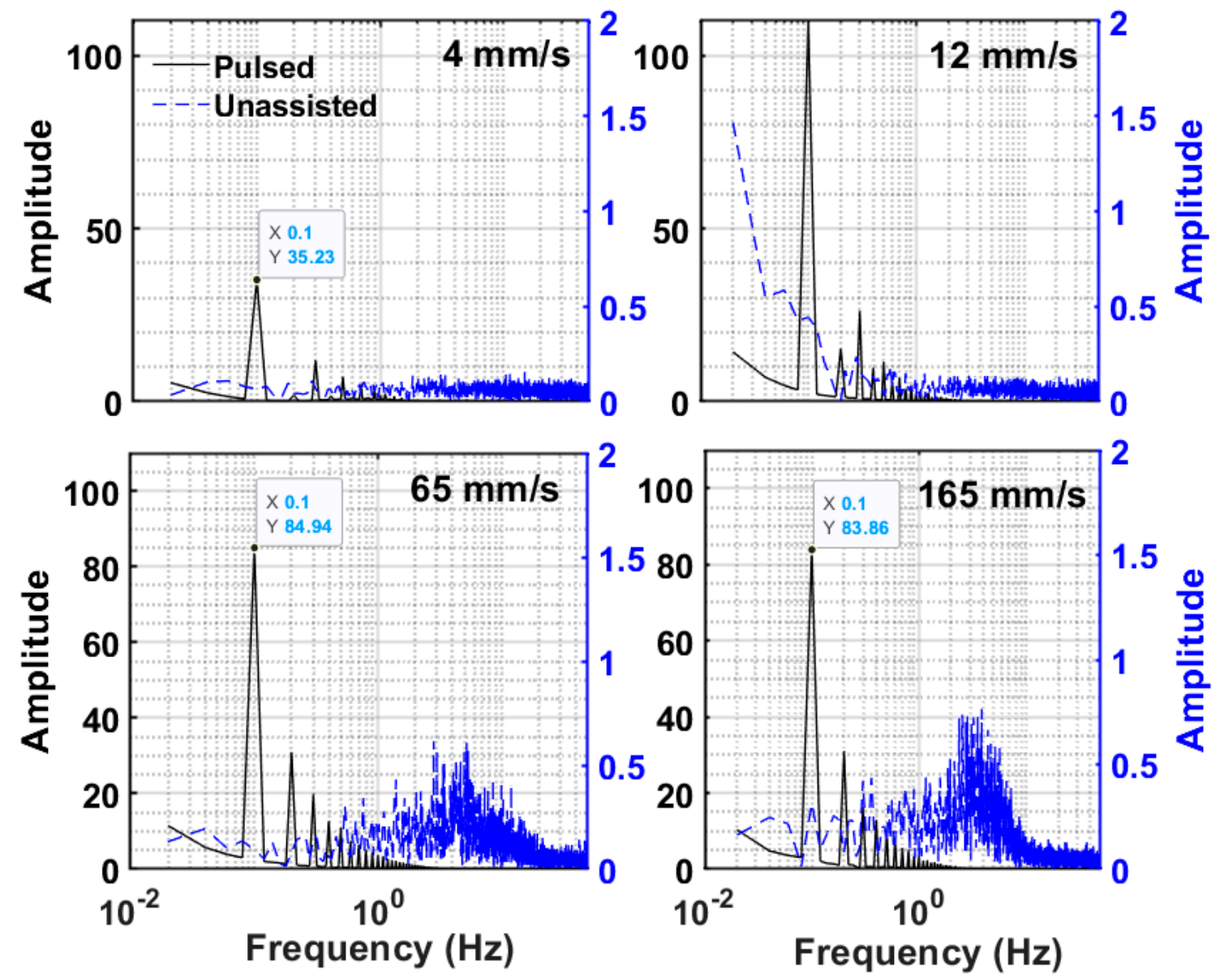

Figure 9. Overall bed dynamics at different velocities for unassisted and pulsed fluidizations.

On the other hand, the square-wave flow pulsations have introduced a prominent peak at $0.1 \mathrm{~Hz}$ for the pulsed fluidized bed. The amplitude of the frequency peak increases when the velocity is increased from $4 \mathrm{~mm} / \mathrm{s}$ to $12 \mathrm{~mm} / \mathrm{s}$ due to an increase in the global pressure drop. Further increase in the velocity to $65 \mathrm{~mm} / \mathrm{s}$ has led to small decrease in the pressure drop due to the fluidization of the solids present in the bed. When the velocity is further increased to $165 \mathrm{~mm} / \mathrm{s}$, the amplitude remains almost unaffected because the pressure drop during fluidization remains unchanged.

Figure 10 compares the bed dynamics of the fluidization and defluidization cycles at four different velocities. Initial non-homogeneities have evidently affected the bed dynamics. The fluidization amplitude at low velocities (e.g., $4 \mathrm{~mm} / \mathrm{s}$ ) is initially higher than the one during the defluidization cycle at the same velocity. The difference is quite significant. Although the same phenomenon is also evident at $12 \mathrm{~mm} / \mathrm{s}$, the difference is not as significant. Note that the bed is incipiently fluidized at $12 \mathrm{~mm} / \mathrm{s}$. When the bed is fully fluidized at $65 \mathrm{~mm} / \mathrm{s}$, the difference in bed dynamics during the fluidization and defluidization cycles is almost negligible. When the velocity is further increased to $165 \mathrm{~mm} / \mathrm{s}$, the bed dynamics between both cycles shows an excellent agreement. 

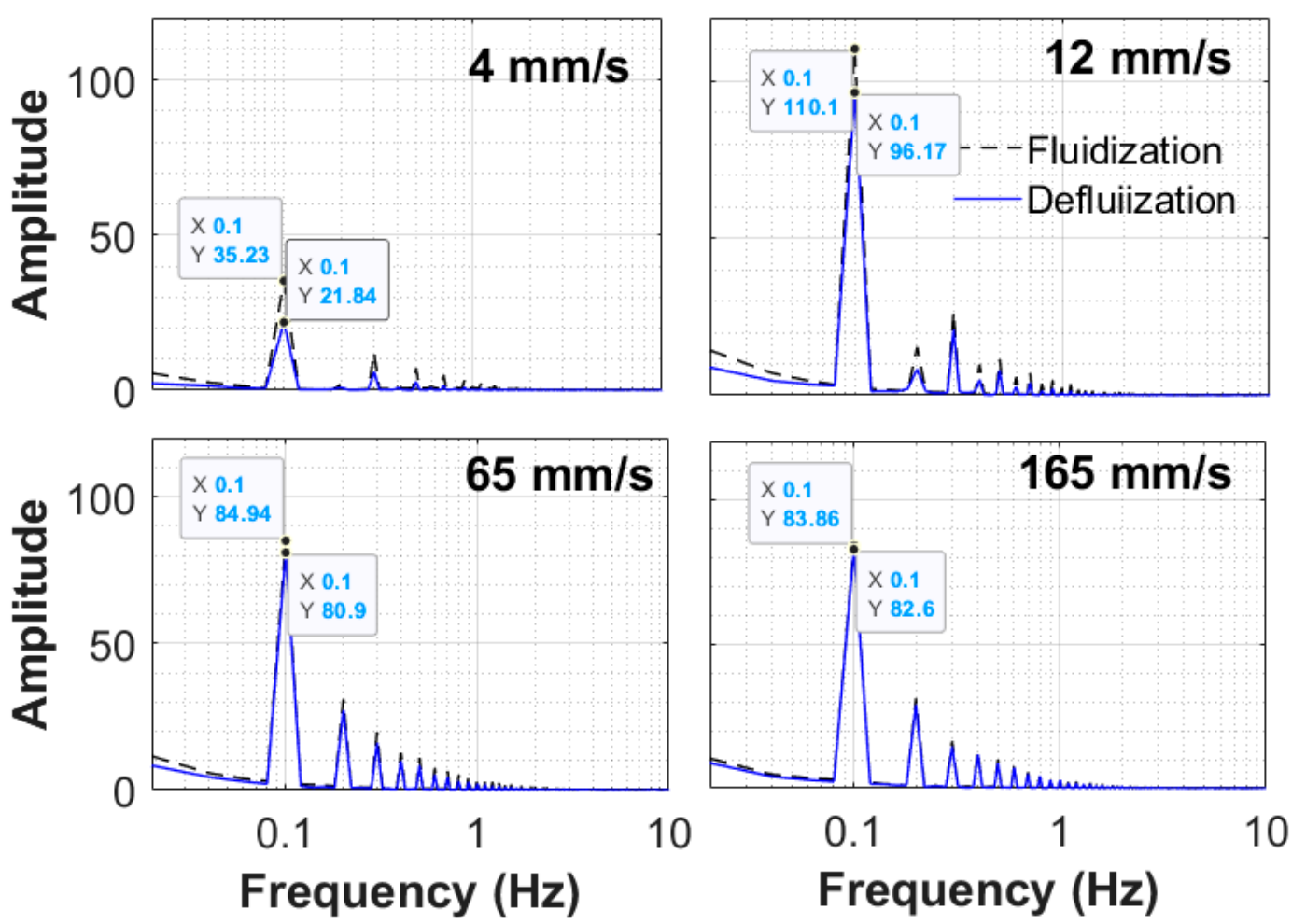

Figure 10. Comparison of frequency responses of overall bed dynamics for fluidization and defluidization at different velocities.

Figure 11 shows the effect of the velocity on the local pressure drops in different regions of the fluidized bed for unassisted and pulsed bed. The velocity dependence of the upper region pressure drop is shown in Figure 11a. The pressure drop of the pulsed fluidized bed is consistently higher than that of the unassisted fluidized bed at all velocities. Note that the pressure drop in a fluidized bed is equal to the effective weight of the solids present between the pressure taps across which the pressure drop is being measured. Thus, higher pressure drop is a clear indication of a greater amount of solids present in the upper region of the pulsed bed than the unassisted fluidized bed. Since the amount of solids loaded for both cases are the same, the greater expansion of the pulsed fluidized bed can be attributed to greater amount of solid particles in the upper region of the pulsed bed. According to the well-known Richardson-Zaki equation, lower terminal velocity yields higher bed expansion, which in turn depends upon the particle diameter. Therefore, greater bed expansion due to pulsation can be attributed to the pulsation induced de-agglomeration resulting in lower terminal velocity as described by the Stokes law. However, greater bed expansion in some cases of vibrated fluidized bed might lead to irreversible coalescence of voids into large bubbles, resulting in an increase in the particle fraction that cannot be predicted using the Richardson-Zaki equation [28]. There was a progressive increase in the pressure drop with the increase in the velocity. Such an increase is caused by the migration of solids from the lower regions of the fluidized bed to the upper region because of the bed expansion.

Figure $11 \mathrm{~b}$ shows the pressure drop profiles for the central region of the pulsed and unassisted fluidized beds. The initial part of the two profiles shows a significant difference. The pressure drop in the case of the pulsed bed is much higher than that of the unassisted bed at the same velocity. The initial part of the pressure drop profiles represents the fixed bed mode of gas-solid contact, wherein the pressure drop is inversely related with the diameter of the solid particle. Consequently, smaller particle size will give rise to higher pressure drops. Therefore, a higher pressure drop for the case of the pulsed fluidization is due to de-agglomeration caused by the flow pulsation. 

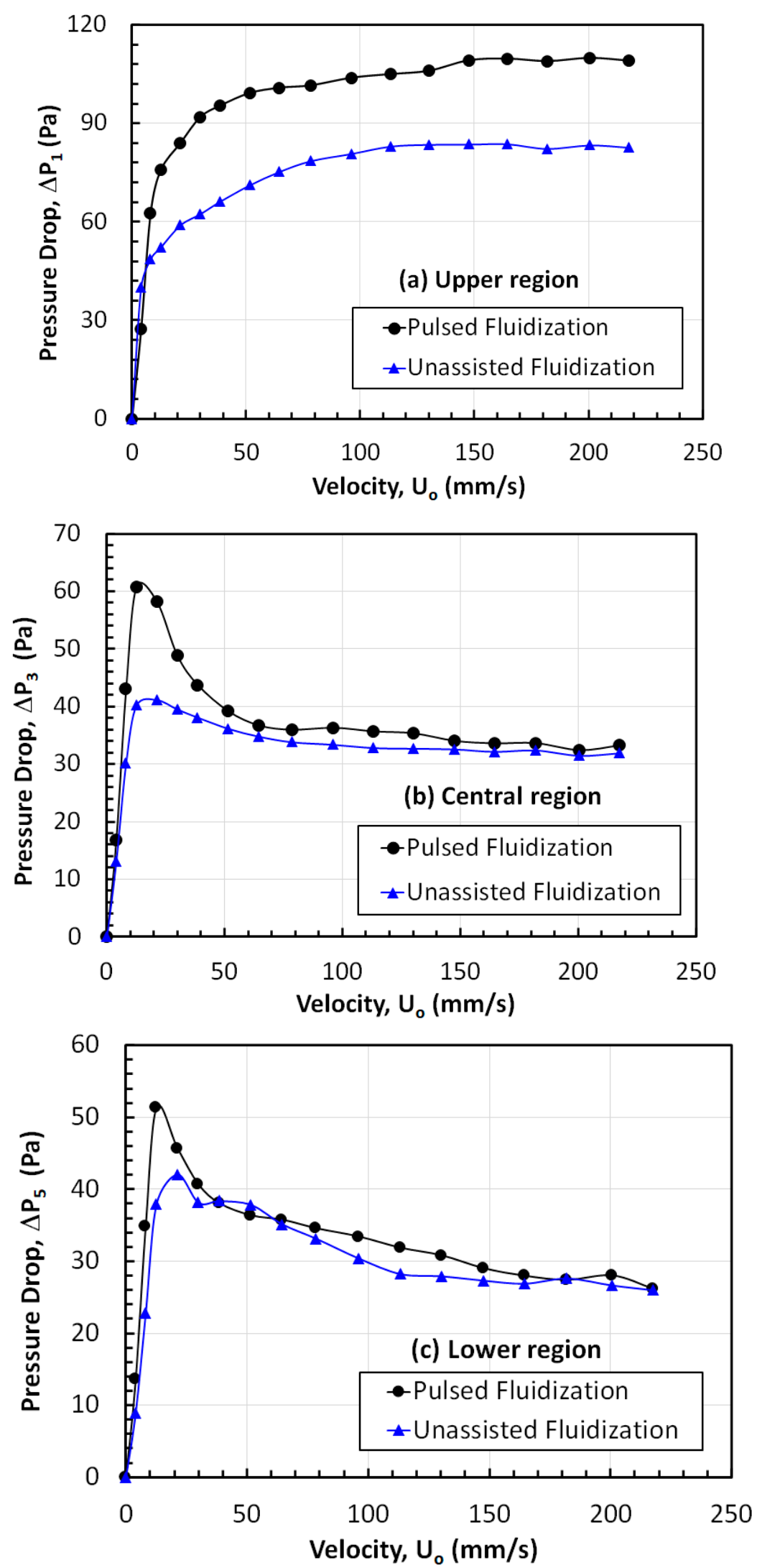

Figure 11. Effect of the velocity on the local pressure drop profiles for unassisted and pulsed fluidized beds during the fluidization cycle, (a) upper region, (b) central region, and (c) lower region. 
Figure 11c compares the pressure drop profiles of the lower region of the unassisted and pulsed fluidized bed. A significant difference in the initial part of the profile is observed owing to the de-agglomeration promoted by the pulsation in the bed. In the fluidized bed mode, the pressure drop is higher due to the elimination of dead zones when the fluidized bed is pulsed.

Figure 12 depicts the global pressure drops for fluidization and defluidization cycles of the experiments. The pressure drops for the pulsed fluidized bed are consistently higher than those of the unassisted fluidized bed. This phenomenon can be attributed to the elimination of non-homogeneities that cause the local gas by-passing through large interstitial spaces of the bed of agglomerated nanosilica due to flow pulsation. The pulsed flow also leads to higher pressure drop than the unassisted flow in the fixed bed mode of gas-solid contact when the velocity is low. This phenomenon arises due to the particle size reduction brought by the deagglomeration caused by the flow pulsation.

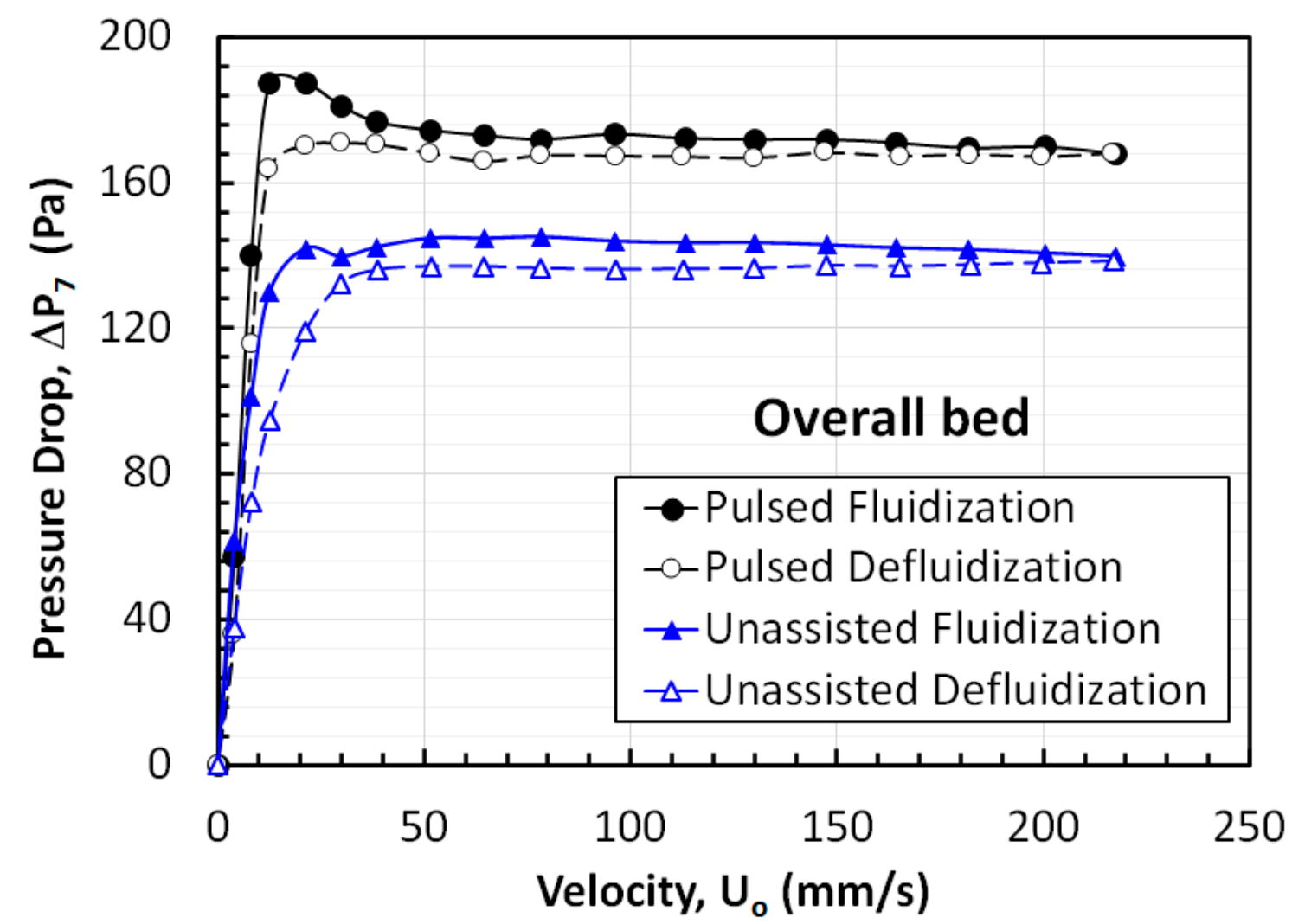

Figure 12. Effect of the velocity on the global pressure drop profiles for unassisted and pulsed fluidized beds during fluidization and defluidization.

An important hydrodynamic parameter of fluidization is the minimum fluidization velocity $\left(\mathrm{U}_{\mathrm{mf}}\right)$. Data of both defluidization experimental runs are presented in Figure 13 for pulsed fluidization and unassisted fluidization. An excellent agreement between the both runs confirms the reproducibility of the experiment data in the present study. The $\mathrm{U}_{\mathrm{mf}}$ values for the unassisted and pulsed fluidized beds are approximately $22 \mathrm{~mm} / \mathrm{s}$ and $11 \mathrm{~mm} / \mathrm{s}$, respectively. Evidently, flow pulsation caused a reduction of approximately $50 \%$ in the minimum fluidization velocity due to the pulsation induced deagglomeration of nanosilica agglomerates. 


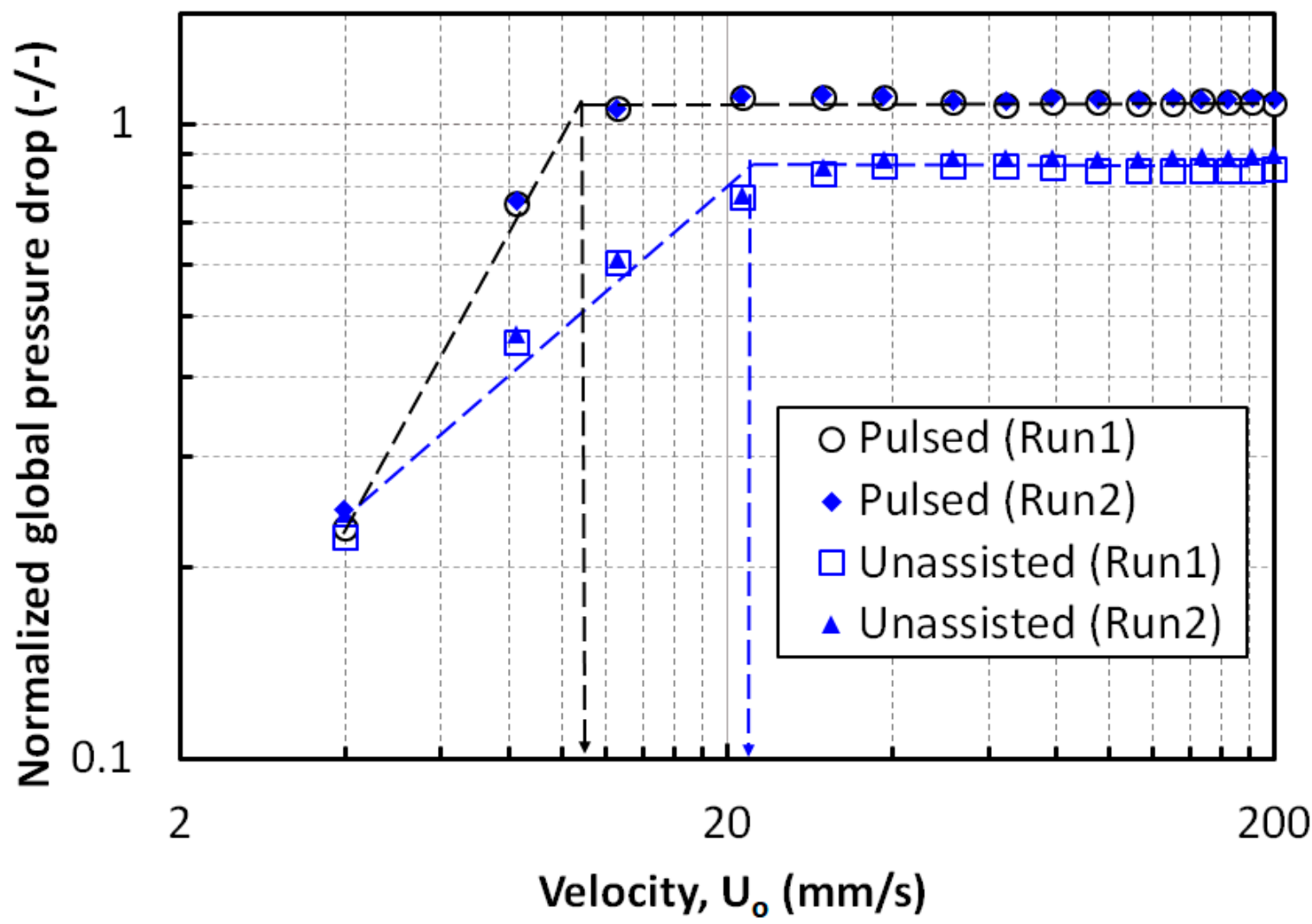

Figure 13. Effect of the velocity on the normalized global pressure drop for the defluidization cycles of unassisted and pulsed fluidizations.

\section{Conclusion}

The hydrodynamics of pulsed fluidized bed was rigorously investigated in this work. The bed was subjected to square wave flow pulsation with adjusted frequency to allow complete collapse of the fluidized bed between two consecutive pulsations. This strategy suppressed non-homogeneities and led to greater expansion of the fluidized bed. Moreover, an approximately $50 \%$ reduction in the minimum fluidization velocity was obtained while the pressure drop in the fixed bed mode of contact was significantly higher for the pulsed fluidized bed at the same superficial velocity of the fluidizing air.

The frequency response analysis provided interesting insights with regard to the bed dynamics. The amplitude of the peak initially increased with the increase in the velocity owing to the increase in the pressure drop. However, when the bed was fully fluidized at a higher velocity, the response of the bed remained apparently unaffected by the change in the velocity. The $0.1 \mathrm{~Hz}$ peak represents the frequency of the pulsation event, while other smaller peaks occurring at higher frequency represent sinusoids used for approximating the square wave pulsation function. Frequency responses at higher velocities showed greater reproducibility between the fluidization and defluidization cycles than those at lower velocities. This difference was observed due to the initial non-homogeneities present in the bed.

Author Contributions: M.A. conceptualization; M.A., and N.S.K. methodology; M.A. and E.H.A.-G. software; M.A., and A.A. validation; M.A., and A.A. formal analysis; E.H.A.-G., M.A., and A.A. investigation; M.A. and N.S.K. resources; E.H.A.-G. data curation; M.A., A.A., and N.S.K. writing-original draft preparation; M.A., A.A., and N.S.K. writing - review and editing; M.A. supervision; M.A. project administration; M.A. funding acquisition. All authors have read and agreed to the published version of the manuscript.

Funding: The Researchers Supporting Project at King Saud University Project No (RSP-2020/42). 
Acknowledgments: The authors would like to thank the Researchers Supporting Project, RSP-2020/42, King Saud University, Riyadh, Saudi Arabia for the financial support.

Conflicts of Interest: The authors declare no conflict of interest. The funders had no role in the design of the study; in the collection, analyses, or interpretation of data; in the writing of the manuscript, or in the decision to publish the results.

\section{References}

1. Geldart, D. Types of Gas Fluidization. Powder Technol. 1973, 7, 285-292. [CrossRef]

2. Lee, J.R.; Lee, K.S.; Park, Y.O.; Lee, K.Y. Fluidization characteristics of fine cohesive particles assisted by vertical vibration in a fluidized bed reactor. Chem. Eng. J. 2020, 380, 122454. [CrossRef]

3. Raganati, F.; Chirone, R.; Ammendola, P. Gas-solid fluidization of cohesive powders. Chem. Eng. Res. Des. 2018, 133, 347-387. [CrossRef]

4. Al-Ghurabi, E.H.; Ali, S.S.; Alfadul, S.M.; Shahabuddin, M.; Asif, M. Experimental investigation of fluidized bed dynamics under resonant frequency of sound waves. Adv. Powder Technol. 2019, 30, 2812-2822. [CrossRef]

5. Chirone, R.; Raganati, F.; Ammendola, P.; Barletta, D.; Lettieri, P.; Poletto, M. A comparison between interparticle forces estimated with direct powder shear testing and with sound assisted fluidization. Powder Technol. 2018, 323, 1-7. [CrossRef]

6. Viscusi, A.; Ammendola, P.; Astarita, A.; Raganati, F.; Scherillo, F.; Squillace, A.; Chirone, R.; Carrino, L. Aluminum foam made via a new method based on cold gas dynamic sprayed powders mixed through sound assisted fluidization technique. J. Mater. Process. Technol. 2016, 231, 265-276. [CrossRef]

7. Si, C.D.; Wu, J.J.; Wang, Y.; Zhang, Y.X.; Liu, G.J. Effect of acoustic field on minimum fluidization velocity and drying characteristics of lignite in a fluidized bed. Fuel Process. Technol. 2015, 135, 112-118. [CrossRef]

8. Zhu, C.; Liu, G.L.; Yu, Q.; Pfeffer, R.; Dave, R.N.; Nam, C.H. Sound assisted fluidization of nanoparticle agglomerates. Powder Technol. 2004, 141, 119-123. [CrossRef]

9. Al-Ghurabi, E.H.; Ajbar, A.; Asif, M. Enhancement of $\mathrm{CO}_{2}$ Removal Efficacy of Fluidized Bed Using Particle Mixing. Appl. Sci. Basel 2018, 8, 1467. [CrossRef]

10. Al-Ghurabi, E.H.; Ajbar, A.; Asif, M. Improving Fluidization Hydrodynamics of Group C Particles by Mixing with Group B Particles. Appl. Sci. Basel 2018, 8, 1469. [CrossRef]

11. Ammendola, P.; Chirone, R.; Raganati, F. Fluidization of binary mixtures of nanoparticles under the effect of acoustic fields. Adv. Powder Technol. 2011, 22, 174-183. [CrossRef]

12. Ajbar, A.; Alhumazi, K.; Asif, M. Improvement of the fluidizability of cohesive powders through mixing with small proportions of group a particles. Can. J. Chem. Eng. 2005, 83, 930-943. [CrossRef]

13. Ajbar, A.; Bakhbakhi, Y.; Ali, S.; Asif, M. Fluidization of nano-powders: Effect of sound vibration and pre-mixing with group A particles. Powder Technol. 2011, 206, 327-337. [CrossRef]

14. Ali, S.S.; Asif, M. Effect of particle mixing on the hydrodynamics of fluidized bed of nanoparticles. Powder Technol. 2017, 310, 234-240. [CrossRef]

15. Ali, S.S.; Basu, A.; Alfadul, S.M.; Asif, M. Nanopowder Fluidization Using the Combined Assisted Fluidization Techniques of Particle Mixing and Flow Pulsation. Appl. Sci. Basel 2019, 9, 572. [CrossRef]

16. Saidi, M.; Basirat Tabrizi, H.; Grace, J.R. A review on pulsed flow in gas-solid fluidized beds and spouted beds: Recent work and future outlook. Adv. Powder Technol. 2019, 30, 1121-1130. [CrossRef]

17. Ireland, E.; Pitt, K.; Smith, R. A review of pulsed flow fluidisation; the effects of intermittent gas flow on fluidised gas-solid bed behaviour. Powder Technol. 2016, 292, 108-121. [CrossRef]

18. Zhou, C.Y.; Dong, L.; Zhao, Y.M.; Fan, X.C. Studies on Bed Density in a Gas-Vibro Fluidized Bed for Coal Cleaning. ACS Omega 2019, 4, 12817-12826. [CrossRef] [PubMed]

19. Akhavan, A.; van Ommen, J.R.; Nijenhuis, J.; Wang, X.S.; Coppens, M.O.; Rhodes, M.J. Improved Drying in a Pulsation-Assisted Fluidized Bed. Ind. Eng. Chem. Res. 2009, 48, 302-309. [CrossRef]

20. Ali, S.S.; Asif, M. Fluidization of nano-powders: Effect of flow pulsation. Powder Technol. 2012, 225, 86-92. [CrossRef]

21. Akhavan, A.; Rahman, F.; Wang, S.; Rhodes, M. Enhanced fluidization of nanoparticles with gas phase pulsation assistance. Powder Technol. 2015, 284, 521-529. [CrossRef] 
22. Ali, S.S.; Asif, M.; Ajbar, A. Bed collapse behavior of pulsed fluidized beds of nano-powder. Adv. Powder Technol. 2014, 25, 331-337. [CrossRef]

23. Ali, S.S.; Al-Ghurabi, E.H.; Ajbar, A.; Mohammed, Y.A.; Boumaza, M.; Asif, M. Effect of Frequency on Pulsed Fluidized Beds of Ultrafine Powders. J. Nanomater. 2016. [CrossRef]

24. Bizhaem, H.K.; Tabrizi, H.B. Experimental study on hydrodynamic characteristics of gas-solid pulsed fluidized bed. Powder Technol. 2013, 237, 14-23. [CrossRef]

25. Dong, L.; Zhou, E.H.; Cai, L.H.; Duan, C.L.; Zhao, Y.M.; Luo, Z.F. Fluidization Characteristics of a Pulsing Dense-Phase Gas-Solid Fluidized Bed for High-Density Separation of Fine Anthracite. Energy Fuels 2016, 30, 7180-7186. [CrossRef]

26. Al-Ghurabi, E.H.; Shahabuddin, M.; Kumar, N.S.; Asif, M. Deagglomeration of Ultrafine Hydrophilic Nanopowder Using Low-Frequency Pulsed Fluidization. Nanomaterials Basel Switz. 2020, 10, 388. [CrossRef] [PubMed]

27. Janssen, L.P.B.M.; Marring, E.; Hoogerbrugge, J.C.; Hoffmann, A.C. The mechanical behaviour of vibrated, aerated beds of glass and starch powder. Chem. Eng. Sci. 1998, 53, 761-772. [CrossRef]

28. Valverde, J.M.; Castellanos, A. Effect of vibration on agglomerate particulate fluidization. AIChE J. 2006, 52, 1705-1714. [CrossRef]

29. Barletta, D.; Donsi, G.; Ferrari, G.; Poletto, M.; Russo, P. The effect of mechanical vibration on gas fluidization of a fine aeratable powder. Chem. Eng. Res. Des. 2008, 86, 359-369. [CrossRef]

30. Barletta, D.; Poletto, M. Aggregation phenomena in fluidization of cohesive powders assisted by mechanical vibrations. Powder Technol. 2012, 225, 93-100. [CrossRef]

31. Zhang, W.; Zhao, M. Fluidisation behaviour of silica nanoparticles under horizontal vibration. J. Exp. Nanosci. 2010, 5, 69-82. [CrossRef]

32. Barletta, D.; Russo, P.; Poletto, M. Dynamic response of a vibrated fluidized bed of fine and cohesive powders. Powder Technol. 2013, 237, 276-285. [CrossRef]

33. Lehmann, S.E.; Hartge, E.U.; Jongsma, A.; deLeeuw, I.M.; Innings, F.; Heinrich, S. Fluidization characteristics of cohesive powders in vibrated fluidized bed drying at low vibration frequencies. Powder Technol. 2019, 357, 54-63. [CrossRef]

34. An, K.; Andino, J.M. Enhanced fluidization of nanosized TiO2 by a microjet and vibration assisted (MVA) method. Powder Technol. 2019, 356, 200-207. [CrossRef]

35. Jia, D.; Cathary, O.; Peng, J.; Bi, X.; Lim, C.J.; Sokhansanj, S.; Liu, Y.; Wang, R.; Tsutsumi, A. Fluidization and drying of biomass particles in a vibrating fluidized bed with pulsed gas flow. Fuel Process. Technol. 2015, 138, 471-482. [CrossRef]

36. Zhao, Z.; Liu, D.; Ma, J.; Chen, X. Fluidization of nanoparticle agglomerates assisted by combining vibration and stirring methods. Chem. Eng. J. 2020, 388, 124213. [CrossRef]

37. Zhu, L.; Lu, H.; Poletto, M.; Liu, H.; Deng, Z. Hopper discharge of cohesive powders using pulsated airflow. AIChE J. 2020, 66, 16240. [CrossRef]

38. Asif, M.; Kalogerakis, N.; Behie, L.A. Hydrodynamics of Liquid Fluidized-Beds including the Distributor Region. Chem. Eng. Sci. 1992, 47, 4155-4166. [CrossRef]

(C) 2020 by the authors. Licensee MDPI, Basel, Switzerland. This article is an open access article distributed under the terms and conditions of the Creative Commons Attribution (CC BY) license (http://creativecommons.org/licenses/by/4.0/). 